\title{
Analysis of Human Resources Management Incentive Mechanism in Public Institutions
}

\author{
Yujie He \\ School of Economics and Management \\ Xi'an University \\ Xi'an, China
}

\begin{abstract}
Under the in-depth reform of the personnel system of public institutions, the importance of the incentive mechanism of human resources management has become increasingly prominent. The effective use of the incentive mechanism will directly affect the work status of the employees of the public institutions, stimulate the enthusiasm of employees, and promote employees to improve work efficiency. However, the effectiveness of the incentive mechanism for human resources management in China's public institutions has not been fully exerted, and the enthusiasm of employees in some institutions has been affected more or less, even hindering the stable development of institutions and the improvement of work efficiency. On the basis of expounding the role of incentive mechanism, this paper analyzes the problems existing in the human resources management of public institutions and measures to improve the incentive mechanism, hoping to promote the development of human resources management in public institutions in China.
\end{abstract}

Keywords-public institutions; human resources management; incentive mechanism

\section{INTRODUCTION}

In the development process of public institutions, although relatively stable human resource management can help prevent brain drain, it is not conducive to the addition of new talents. In the social and economic development, the status and role of public institutions have become increasingly prominent. Under the premise of doing a good job in human resources management, public institutions can guarantee their stable development. However, due to some objective problems in human resource management, it is difficult to improve the management efficiency, and it is not conducive to mobilizing the enthusiasm of employees. Therefore, it is very necessary to establish and improve the incentive mechanism for human resources management in public institutions.

\section{Purposes of Establishing InCENTIVE MECHANISM}

The existing management system of public institutions reflects weak or lack of responsibility, rigid thinking and excessive management, which is contrary to the "peopleoriented" thought of contemporary human resource management. The long-term "career type" has left some "sequelae" to the institutions, such as the lack of flexibility in the employment system, the coexistence of surplus and shortage in the talent structure as well as the severe phenomenon of the seniority system. All of these are not conducive to improving the enthusiasm and potential of employees. To change these negative thoughts and behaviors and fully mobilize the initiative and enthusiasm of employees, managers must strengthen the education and guidance of employees and establish effective incentive mechanism. Only by stimulating the enthusiasm of employees to manage public affairs, can it be possible to constantly improve their governance ability and innovative thinking, and can they effectively manage social affairs, serve the people and perform the public functions of the government. Through effective incentives, the initiative of employees in public institutions can be better mobilized and the ability of public management and the level of administrative services can be consciously improved.

\section{THE ROLE OF INCENTIVE MECHANISM IN THE MANAGEMENT OF HUMAN RESOURCES IN PUBLIC INSTITUTIONS}

\section{A. Mobilizing the Enthusiasm of Employees}

The application of incentive mechanism in the human resource management of public institutions can fully mobilize the enthusiasm of employees, and at the same time clarify the work objectives to ensure the smooth completion of work tasks. At present, the remuneration of public institutions is constantly improving, which to a certain extent is conducive to employees' work enthusiasm. In addition, the development of an effective incentive mechanism can also effectively enhance the ability of employees and contribute to the long-term development of public institutions

\section{B. Attracting Outstanding Talents to Join Public Institutions}

When a public institution develops an incentive mechanism, it should consider more about the real material reward for employees. Through effective incentives, public institutions can recruit more outstanding talents during the selection of talents, and gradually improve the overall quality of the talent team of the institutions. At the same time, in the human resources management work, the implementation of the corresponding incentives can also encourage employees 
to work energetically and make greater contributions to the development of the institutions.

\section{Standardizing the Employees' Behavior}

The incentive mechanism has certain binding force in view of the work behavior of employees in public institutions, which can enhance the sense of identity of employees to wholeheartedly plough into the work to achieve self-worth. Implement an effective incentive mechanism in the human resources management of public institutions, so that each employee consciously abides by various rules and regulations, and strives to obtain the approval of others as much as possible, so as to love their own work more and create and maintain a good work order.

\section{Enhancing the Cohesiveness}

In the human resources management of public institutions, the introduction of incentive mechanism can foster a sense of collective honor for employees, enhance the cohesiveness, and contribute to the development of public institutions. At the same time, the incentive mechanism provides employees with a platform to achieve self-worth, guide employees to clear their own space for improvement, reasonably set goals, and achieve progress and growth in chasing. In addition, the incentive mechanism can also enhance the cohesiveness of employees in the public institutions, create a positive working atmosphere, and stimulate the enthusiasm of employees, thus effectively improving the efficiency of them.

\section{PRoblems IN THE INCENTIVE MECHANISM OF Human Resources Management in CHINESE PubliC INSTITUTIONS}

\section{A. The Incentive Concept of Human Resource Management Is Relatively Backward}

At present, in the human resource management of public institutions in China, the problem of employee salary distribution is more prominent and its main performance is the backwardness of wage distribution. For the employees of the public institutions, the salary is relatively fixed. No matter how good their performance is or how hard they work, the salary is the same. This practice weakens the enthusiasm of the employees to a certain extent. This shows that the current salary distribution model of public institutions is not conducive to the mobilization of employees' enthusiasm.

In the long-term development process, China's public institutions have formed an "administrative" human resource management concept, believing that employees are subordinates of the unit, and do not regard employees as the driving force of the unit's development. There is a certain similarity between the management concept of the public institution and that of government departments. This management concept greatly affects the human resources management of the public institutions in China, resulting in a lack of incentive mechanism for the public institutions, which affects the work efficiency of institutions and the performance of employees. Therefore, China's public institutions need to make breakthroughs in this link, and add more incentives to the process of human resources management, so that every employee of the institution has a strong sense of belonging and responsibility and make positive contributions to the healthy development of the public institutions.

\section{B. The Lack of Diversity of Incentive Methods and Perfect Performance Appraisal System}

With the development of social economy, some institutions have realized the importance of implementing the performance appraisal system. However, in the actual work process, there will be phenomena such as "the implementation is not in place and the evaluation results are not satisfactory". The leadership of Chinese institutions generally has administrative responsibilities, and lots of administrative elements are added in the management work, which leads to the lack of diversity in the management of the institutions, and the incentive methods are even difficult to change. Such management mode is difficult to adapt to the current development of public institutions, and it is harmful to employees. Moreover, these problems will lead to the collective loss of outstanding talents in public institutions in China and transfer to other industries. In addition, when the performance appraisal is carried out, the public institutions do not conduct assessments based on the actual situation of the employees. The implementation of the assessment system lacks an effective evaluation system, which can't motivate employees. Therefore, the incentive mechanism of Chinese institutions needs to be changed to enhance the richness of incentive methods. Let more employees experience the efforts of the leadership and let all employees work toward the same goal.

\section{The Incentive Mechanism Lacks Fairness and Has Not Been Implemented in Place}

The nature of public institutions is quite special. In the long-term operation process, a relatively fixed working mode has been formed. In terms of human resources management, the uniformity of management is strong, but the management level is not strong and there is insufficient equity for employees in different departments. The job nature of public institutions will include the nature of the technology, the nature of administration, the nature of the service, etc. The work content of these departments is different and if the same incentive mechanism is used, it will not have a positive effect on all employees in the department. There are also big differences in the compensation that employees receive and this is not because of the difference in employee performance, but because of unreasonable incentives. Therefore, the incentive mechanism should be appropriately changed to improve its fairness to retain more outstanding employees. In the human resources management of public institutions, the full implementation of the incentive mechanism is very necessary, which can stimulate the enthusiasm of employees to a certain extent, and encourage employees to devote themselves to their work, so as to establish a good image of public institutions and make contributions to social and economic development. However, in actual work, due to the lack of fairness in the incentive 
mechanism, the implementation of incentive mechanisms for public institutions is not in place, and its positive role is not fully realized.

\section{EFFECTIVE STRATEGIES OF IMPLEMENTING INCENTIVE MECHANISMS FOR HUMAN RESOURCES MANAGEMENT IN PUBLIC INSTITUTIONS}

\section{A. Keeping to the Principle of Fairness and Gradually Optimizing the Way of Salary Distribution}

For public institutions, the principles of justice, openness and fairness are the basis of incentive work. Firstly, the incentive criteria should be clear and strictly in accordance with the standards. Secondly, be realistic about the practice of rewards and punishments and objectively evaluate the work of employees. Finally, clarify the rules of rewards and punishments and on this basis motivate employees to work better. At present, the wages of employees in China's public institutions are mainly derived from state and local financial allocation, mainly including wages and social insurance. For a long time, China's public institutions have continuously adjusted and improved the salary distribution system. However, in actual work, the salary distribution of some institutions is not entirely based on employee contributions, and the institutions also consider other factors such as employees' titles and their working time. Therefore, public institutions must strengthen the reform of the compensation system, innovate the distribution model, and achieve incentive mechanisms.

\section{B. Setting the Incentive Mechanisms Centering on Employees}

At present, the incentive mechanism for the construction of public institutions is based on Maslow's hierarchy of needs. In order to implement the incentive system smoothly, public institutions must first understand the needs of employees. Maslow's hierarchy of needs divides human needs into five levels: physiology, social contact, security, self-fulfillment and respect. These five aspects don't exist independently, but can freely transform different levels of needs on the basis of mutual promotion. When formulating incentive measures, public institutions must have a detailed understanding of the work motivation and needs of employees, and develop effective incentives based on the needs of employees, on the basis of which can motivate employees' work enthusiasm and explore the potential of them.

\section{Innovating Employees's Incentive Concept}

Ideas are guides to actions. So public institutions should strengthen the construction of incentive mechanisms in human resource management, and the primary task of the human resources management incentive concept should be the innovation. Therefore, public institutions should take the strategic goal and deployment of "Strengthening the Country with Talents" as the goal, and explore the incentive mechanism corresponding to the reform, innovation and development of the unit according to the actual needs of the personnel of the unit. The incentive mechanism should be further studied and actively innovated, especially by referring to the advanced experience of external enterprises and institutions in human resource management incentive, so as to construct multi-factor, diversified and multi-leve incentive mechanism. At the same time, public institutions should actively implement the talent development strategy, formulate the corresponding talent incentive planning and operation mode, to ensure a certain long-term and strategic human resources incentive system, and on this basis, effectively improve the operability and efficiency of human resources incentive in public institutions.

\section{Implementing Diversified Incentives}

With the development of social economy, modern management mode has emerged constantly. It is very necessary for public institutions to dig into new incentive methods and stimulate employees' working enthusiasm so as to continuously improve the incentive mechanism in human resource management. Public institutions should combine the development characteristics of the unit and develop effective human resource management incentives. The general incentives mainly include compensation, training, and social insurance. In actual work, public institutions can combine these tools to achieve human resource management goals. In addition, the leaders of public institutions should regularly communicate with employees to know about the work situation and difficulties encountered by the employees, so as to effectively promote the stable implementation of the incentive mechanism.

\section{E. Promoting the Organic Combination of the Unit Culture and the Incentive Mechanism}

The culture of public institutions is a kind of spiritual culture gradually formed in its long-term management. It has certain constraints and guiding effects on employees behavior. A good culture can guide employees to consciously regulate their behavior, enhance team awareness, and abandon unqualified and injurious behavior. Public institutions integrate their own culture and incentive mechanism; enhance employees' sense of honor and internal cohesiveness so as to provide a guarantee of positive energy for the development of public institutions.

\section{F. Gradually Improving the Performance Appraisal Methods}

When formulating performance appraisal mechanisms, public institutions must adhere to the principles of justice, fairness, science, and rationality. It is necessary to formulate a matching assessment system for the needs of different positions, and at the same time, performance assessment standards should be formulated according to the functions of different posts and performance assessment results, so as to prevent the influence of subjective consciousness of performance appraisers. In addition, it is also necessary to ensure that the rewards and punishments are clearly defined in the performance appraisal of employees, and special personnel should be assigned to monitor and manage to ensure that the public institutions fully exert their incentives in performance appraisal. 


\section{CONCLUSION}

In summary, with the development of social economy, people's management requirements for government departments are getting higher and higher. At the same time, the demand for talents from public institutions has been increasing. In order to prevent the loss of talents and better serve the society and the people, it is necessary for public institutions to strengthen and improve the human resources management incentive system. And on this basis to promote public institutions better conform to the trend of the times and stabilize the social development. In addition, in order to promote the better development of employees, the public institutions should mobilize the enthusiasm of employees as much as possible, enhance the employees' centripetal force towards the units, clarify the development goals, and improve the work efficiency and on this basis, promote the long-term development of the units so as to better serve the society and the people.

\section{REFERENCES}

[1] Han Xun. Exploration on the Compensation Management and Salary Incentive Mechanism of Institutions [J]. Industry and Technology Forum, 2015 (15).

[2] Shao Shuai. On the Status Quo and Countermeasures of Human Resources Management in Government Institutions [J]. The Intelligence, 2019(12): 246.

[3] Yin Sheng. Incentive Mechanism in Human Resources Management of Institutions [J]. Accounting Learning, 2019(10): 184+186.

[4] Wang Haosheng. The Application of Performance Incentive Mechanism in Human Resources Management of Institutions [J]. Technology and Market, 2019, 26(03): 204-205.

[5] Li Wenzheng. Further Thinking on Strengthening the Human Resources Management of Public Institutions [J]. Hebei Enterprise, 2018(11): 124-125.

[6] You Shilan. The Application of Incentive Theory in Human Resources Management of Public Institutions [J]. National Circulation Economy, 2018(29): 61-62.

[7] Zhang Li. Problems and Countermeasures of the Performance Appraisal System in the Human Resources of Public Institutions [J]. China Market, 2018(25): 89-90.

[8] Xiao Quanhua. The Application of Performance Incentive Mechanism in Human Resources Management of Public Institutions [J]. Modern Economic Information, 2018(13): 102.

[9] Yao Qing. Exploration on the Application and Significance of Incentive Mechanism in the Economic Management of Human Resources in Public Institutions (English and Chinese), 2018(09): 174. 